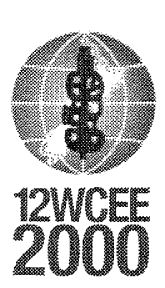

2833

\title{
SEISMIC HAZARD EVALUATION
}

\author{
PAUL SOMERVILLE ${ }^{1}$
}

\begin{abstract}
SUMMARY
This paper reviews concepts and trends in seismic hazard characterization that have emerged in the past decade, and identifies trends and concepts that are anticipated during the coming decade. New methods have been developed for characterizing potential earthquake sources that use geological and geodetic data in conjunction with historical seismicity data. Scaling relationships among earthquake source parameters have been developed to provide a more detailed representation of the earthquake source for ground motion prediction. Improved empirical ground motion models have been derived from a strong motion data set that has grown markedly over the past decade. However, these empirical models have a large degree of uncertainty because the magnitude - distance - soil category parameterization of these models often oversimplifies reality. This reflects the fact that other conditions that are known to have an important influence on strong ground motions, such as nearfault rupture directivity effects, crustal waveguide effects, and basin response effects, are not treated as parameters of these simple models. Numerical ground motion models based on seismological theory that include these additional effects have been developed and extensively validated against recorded ground motions, and used to estimate the ground motions of past earthquakes and predict the ground motions of future scenario earthquakes. The probabilistic approach to characterizing the ground motion that a given site will experience in the future is very compatible with current trends in earthquake engineering and the development of building codes. Performance based design requires a more comprehensive representation of ground motions than has conventionally been used. Ground motions estimates are needed at multiple annual probability levels, and may need to be specified not only by response spectra but also by suites of strong motion time histories for input into time-domain non-linear analyses of structures.
\end{abstract}

\section{INTRODUCTION}

As a result of the plate tectonics revolution in the 1960's and the ensuing decades of intensive research in the earth sciences, the long term earthquake potential of most parts of the world, especially near plate boundaries, is fairly well understood. As a result, earth scientists have a partial understanding of the long-term seismic behavior of some of the more active faults. However, with few exceptions, large earthquakes do not appear to occur at uniform time intervals, or to rupture exactly the same segment of a fault from one earthquake to the next. Consequently, even for sites near the best understood faults, earth scientists are not able to predict where and when the next large earthquake is going to occur, and so a probabilistic approach to seismic hazard evaluation is most compatible with our state of knowledge of seismic potential. Even greater uncertainty exists in most other regions of the earth, where the locations of potentially active faults are poorly known or unknown, and their seismic potential is poorly understood.

There is also a large degree of uncertainty in the level of the ground motion that a specified earthquake will generate at a particular site, and this uncertainty usually dominates the uncertainty in the seismic hazard estimate at the site. Developments in theoretical and computational seismology during the past two decades have provided significant insights into the causes of this variability in ground motions, and are now being used to reduce it. 
Conventional ground motion models predict ground motion parameters using a simplified model in which the effects of the earthquake source are represented by earthquake magnitude; the effects of wave propagation from the earthquake source to the site region are specified by a distance; and the effects of the site are specified by a site category. These ground motion models have a large degree of uncertainty because other conditions that are known to have an important influence on strong ground motions, such as near-fault rupture directivity effects and the response of sedimentary basins, are not treated as parameters of these simple models. In order to reduce the uncertainty in ground motion prediction at a given site, the parameterization of ground motion models is being augmented to include more realistic representations of source, path and site effects.

For some purposes, the strong ground motions expected at a site are represented by those resulting from a single earthquake. For example, ground motion maps of future scenario earthquakes have played an important role in urban planning and mitigation activities. Also, seismic hazards for the design of critical facilities are sometimes characterized using a deterministic approach, which usually consists of a worst case scenario earthquake. Deterministic estimates of ground motions are typically made for a single controlling earthquake whose magnitude (and possibly other source parameters) and closest distance are specified. Since the ground motions from only one earthquake are considered, the uncertainty in the estimated ground motions depends on detailed aspects of the earthquake source, the wave propagation path between the source and the site, and the site response.

Given the uncertainty in the timing, location and magnitude of future earthquakes, for most engineering purposes it is more meaningful to use a probabilistic approach to characterizing the ground motion that a given site will experience in the future than to use a scenario earthquake. A probabilistic seismic hazard analysis takes into account the ground motions from the full range of earthquake magnitudes that can occur on each fault or source zone that can affect the site. This information is numerically integrated using probability theory to produce the annual frequency of exceedance of each different ground motion level for each ground motion parameter of interest (Cornell, 1968; Kulkarni et al., 1979).

The probabilistic approach to seismic hazard characterization is very compatible with current trends in earthquake engineering and the development of building codes, which have embraced the concept of performance based design. Examples of conceptual frameworks for performance based design include Vision 2000 (SEAOC, 1996), FEMA-273 (FEMA, 1997), and EERI (1998). In contrast to the traditional building code approach, performance-based design requires an explicit prediction of the structure's performance at each of several ground motion levels corresponding to a set of performance objectives. The performance objectives may range from continued function of the building during relatively small, frequent ground motions; to limiting damage below the life safety threshold in severe, less frequent ground motions; to prevention of collapse for very severe, infrequent ground motions. Each performance objective is associated with an annual probability of occurrence, with increasingly undesirable performance characteristics caused by increasing levels of strong ground motion having decreasing annual probability of occurrence.

Performance based design requires a more comprehensive representation of ground motions than do most current design procedures. It requires the specification of the ground motions at multiple annual probability levels. Also, the ground motions may need to be specified not only by response spectra but also by suites of strong motion time histories for input into time-domain non-linear analyses of structures. This is because response spectrum analysis, upon which nearly all current structural design is based, uses a linear elastic model and therefore does not address the non-linear response that is the essence of building damage and failure.

\section{EARTHQUAKE SOURCE CHARACTERIZATION FOR GROUND MOTION PREDICTION}

In a seismic hazard evaluation for a given site, it is necessary to identify the seismic sources on which future earthquakes are likely to occur, to estimate the magnitudes and frequency of occurrence of earthquakes on each seismic source, and to identify the distance and orientation of each seismic source in relation to the site. If a deterministic approach is used to characterize the ground motions, then a single scenario earthquake is usually used to represent the seismic hazard, and its frequency of occurrence does not directly influence the level of the hazard. If a probabilistic approach is used, then the ground motions from a large number of possible earthquakes are considered, and their frequencies of occurrence are key parameters in the analysis. 
Modern ground motion models recognize differences in ground motions for different tectonic categories of earthquakes. These categories include crustal earthquakes in tectonically active regions, crustal earthquakes in tectonically stable regions, earthquakes on subduction plate interfaces, and earthquakes occurring within subducted slabs. Earthquake sources may be characterized as discrete faults, or as zones having uniform seismic potential. In tectonically active regions, it is usually possible to identify discrete earthquake faults. The regions surrounding these faults typically have some level of seismic activity, and are characterized by distributed source zones having uniform seismic potential. In moderately active regions, these distributed seismic zones often dominate the probabilistic seismic hazard even when identified faults are also present. In tectonically stable regions, all of the seismic sources may be characterized by distributed seismic zones.

The size of the earthquake is characterized by its magnitude or seismic moment. Earthquake size is most conveniently characterized by seismic moment (or moment magnitude), because the seismic moment is directly related to the product of the fault rupture area and average fault displacement. Thus the seismic moment of an earthquake on a given fault can be directly estimated from fault-specific estimates of the fault length, fault width and average displacement. Alternatively, the seismic moment can be estimated from empirical relationships between seismic moment and fault parameters such as fault area, fault length, and average displacement that are based on the average properties of a large number of earthquakes (Wells and Coppersmith, 1994; Somerville et al., 1999). The most reliable method of estimating seismic moment is from fault area.

In order to identify the distance between the source and the site, the dimensions of the fault for a given magnitude need to be specified. Line source representation of distant sources may be adequate, but the fault dimensions both along strike and downdip may need to be specified for measuring the distance to the site when the source is close to the site. In some ground motion models, additional source parameters specifying the dimensions and geometry of the source, the location of the site in relation to the source, and the location of the hypocenter, are required for representing near fault effects such as rupture directivity effects and hanging wall effects, which are described later.

If numerical simulation methods are used to estimate the ground motions, then the spatial distribution of slip on the fault and the time function of slip on the fault also needs to be characterized. Detailed studies of the spatial distribution of slip on the fault plane for earthquakes in tectonically active regions, derived from strong motion recordings and other data, have shown that the slip distribution is highly variable, characterized by asperities (regions of large slip) surrounded by regions of low slip. These slip models have been used to develop relationships between seismic moment and a set of fault parameters that are needed for predicting strong ground motions (Somerville et al., 1999). These parameters include fault length, fault width, rise time (duration of slip at a point on the fault), and the size, slip contrast and location of asperities.

When the ground motions for evaluation and design are characterized by a scenario earthquake, the primary earthquake source parameter is the magnitude or seismic moment of the scenario earthquake. In a deterministic analysis, the scenario earthquake is typically the largest earthquake that is expected to occur on the source that controls the seismic hazard. The evaluation of the largest earthquake is complicated by the fact that fault systems are often composed of segments. While these segments may usually rupture individually with characteristic magnitude earthquakes (Schwartz and Coppersmith, 1984), they may also rupture together in cascades, producing larger earthquakes than the characteristic events, as occurred in the 1992 Landers, California earthquake (Wald and Heaton, 1994). The maximum earthquake magnitude thus has uncertainty associated with it, as do the other parameters used in seismic hazard analysis, and is best handled using a logic tree approach in a probabilistic seismic hazard analysis.

When the ground motions for evaluation and design are characterized probabilistically, the source characterization described above is repeated for earthquakes of all magnitudes on each potential seismic source. The uncertainties in the source parameters are addressed formally through the use of logic trees (Kulkarni et al., 1984). In principle, the probabilistic analysis can make use of all of the detailed aspects of source characterization that may be used in a deterministic analysis, although in practice this may not be done.

Probabilistic analysis requires an important category of additional information: the expected frequencies of occurrence of earthquakes of various magnitudes on each potential seismic source. This information can be represented by the total seismic moment release rate on the source, together with an earthquake recurrence model that describes the partition of this seismic moment release rate into earthquakes of different seismic moment. The seismic moment release rate on a fault is given by the product of the fault area, the slip rate, and the shear modulus of the seismogenic zone. 
The seismic moment release rate can be derived from one or more of three distinct categories of data. The first category, historical seismicity, is most reliable in tectonically active regions that have a relatively long historical earthquake record, and may be applicable to both individual faults and to a region. Historical seismicity can also be used to constrain the distribution of earthquake magnitudes, especially in the low magnitude range. The second category, slip rates of active faults, is usually only available in tectonically active regions, and is applicable to individual faults. Additional geological data, such a slip per event and average recurrence interval of events, may be used to constrain the distribution of earthquake magnitudes, especially in the high magnitude range. The third category, geodetic strain rates, is in principle available in all tectonic environments and can be used to constrain the seismic moment rate over an extended region. Additional information is needed to partition the geodetic strain rate over individual faults, and to constrain the distribution of earthquake magnitudes. Methods of integrating historical seismicity, geological slip rates, and geodetic measurements for characterizing earthquake recurrence are described by Ward (1994).

Earthquake recurrence is usually represented by one of two models in seismic hazard analyses (Youngs and Coppersmith, 1985). In the modified or truncated Gutenberg-Richter relationship (Gutenberg and Richter, 1964), the number of events is inversely proportional to the seismic moment of the event, and is truncated at the maximum magnitude. In the characteristic recurrence relationship (Schwartz and Coppersmith, 1984), a truncated GutenbergRichter relationship, representing the occurrence of small and moderate earthquakes, is combined with a characteristic earthquake relationship, representing the occurrence of large earthquakes, which has a specified magnitude range and rate of occurrence. This rate of occurrence is higher than the extrapolated value of the truncated Gutenberg-Richter relationship. The truncated Gutenberg-Richter relationship is usually an appropriate representation of the seismicity of regions containing faults of various sizes. The characteristic recurrence model is usually an appropriate representation of the seismicity of individual faults.

If the seismicity of a source is based solely on historical seismicity, then the seismic moment rate of the source depends on the maximum earthquake magnitude in the earthquake recurrence model. In this case, the larger the maximum magnitude, the higher the calculated hazard. However, if the seismicity of the source is constrained by geologic slip rates or geodetic strain rates, the maximum earthquake in the earthquake recurrence model affects the calculated seismic hazard in a different way. Since there is a fixed seismic moment rate budget, selection of a larger maximum magnitude results in lower rates of occurrence of smaller events, and the calculated seismic hazard may be reduced (Youngs and Coppersmith, 1985).

\section{GROUND MOTION PREDICTION MODELS}

\section{Empirical Ground Motion Models}

The simplest ground motion attenuation relations predict ground motion parameters using a simplified model in which the effects of the earthquake source are represented by earthquake magnitude; the effects of wave propagation from the earthquake source to the site region are specified by a distance; and the effects of the site are specified by a site category (Table 1).

Moment magnitude is the most appropriate measure of earthquake size, because it is directly related to the seismic moment of the earthquake, and thus to the fault area and the average displacement on the fault. When earthquake occurrence rates are instead based on historical seismicity in seismic hazard analyses, other magnitude measures are sometimes used because the seismic moments of the historical earthquakes may be poorly known.

The distance between the source to the site is measured in a variety of different ways, including closest distance to the rupture surface, closest distance to the seismogenic rupture surface, closest distance to the vertical projection of the rupture to the surface, and hypocentral distance, as summarized by Abrahamson and Shedlock (1997). The lack of a standard definition of distance hinders the comparison and use of multiple ground motion attenuation relations, which is necessary to fully account for uncertainty in estimated ground motions. 
Table 1. Ground Motion Prediction Methods

\begin{tabular}{|l|l|l|l|}
\hline METHOD & SOURCE & PATH & SITE \\
\hline EMPIRICAL & Seismic Moment & Distance & Geological category \\
\hline STOCHASTIC & $\begin{array}{l}\text { Source spectrum, e.g. } \\
1 \text { corner (Brune) } \\
\text { or 2 corners (Atkinson) }\end{array}$ & $\begin{array}{l}\text { Attenuation function e.g. 1/R - } \\
1 / \mathrm{R}^{1 / 2} \text {, or empirical. Duration varies } \\
\text { with R. Anelastic Q. } \\
\text { No distinct body waves or surface } \\
\text { waves. }\end{array}$ & Kappa or fmax \\
\hline $\begin{array}{l}\text { BROADBAND } \\
\text { GREEN'S } \\
\text { FUNCTION }\end{array}$ & $\begin{array}{l}\text { Shear dislocation, slip time } \\
\text { function specified on fault }\end{array}$ & $\begin{array}{l}\text { Green's functions } \\
\text { including body waves, surface } \\
\text { waves, anelastic Q. }\end{array}$ & $\begin{array}{l}\text { Kappa; empirical or } \\
\text { theoretical receiver } \\
\text { function }\end{array}$ \\
\hline
\end{tabular}

Site categories are usually based either on geological criteria or on shear wave velocity of the surficial materials. The use of shear wave velocity has the advantage of being based on an objective measure which affects ground motions in a way that can be modeled. However, it cannot be directly applied to sites that lack shear wave velocity measurements. Also, deeper geological structure such as sedimentary basins and laterally varying structure may have an equally strong or even stronger effect on site response.

A major shortcoming of existing attenuation relations is the lack of a standard definition of site categories. Consequently, a large source of difference in the ground motion models of different investigators lies in the different criteria that are used for site conditions, and in the assignment of site categories to individual recording sites. The use of a standard site classification system, and the assignment of these categories to individual recording stations, has the potential to reduce these unnecessary discrepancies between different model predictions. The important effect of nonlinear soil behavior on site response is recognized in the site response factors that are embodied in current building codes and provisions in the United States such as the 1997 UBC (SEAOC, 1996) and 1997 NEHRP (FEMA, 1998) provisions.

During the past several decades, large sets of strong motion recordings were obtained from numerous earthquakes, significantly expanding the data base of strong motion recordings available for the derivation of empirical ground motion models. A collection of recent models based on recorded data and in some cases on seismological models, accompanied by an overview (Abrahamson and Shedlock, 1997), was published in Seismological Research Letters. These ground motion models are for distinct tectonic categories of earthquakes: shallow crustal earthquakes in tecionically active regions; shallow crustal earthquakes in tectonically stable regions; and subduction zone earthquakes, which are subdivided into those that occur on the shallow plate interface, and those that occur at greater depths within the subducting plate. Strong ground motions from subduction earthquakes generally attenuate more gradually with distance than crustal earthquakes, and earthquakes occurring with the subducting slab produce stronger ground motions than those occurring on the subduction interface (e.g. New Zealand: McVerry et al., 1999; Japan: Kobayashi et al., 2000). Mixing data from different earthquake categories gives rise to attenuation relations that overpredict the ground motions from some tectonic categories of earthquakes and overpredict those from others.

Recent peak acceleration attenuation relations are characterized by the following features. There is a "distance saturation" in which the slope of the attenuation function decreases at close distances, reflecting the fact that the earthquake is a distributed source, not a point source. For related reasons, there is a "magnitude saturation" in which the ground motions increase more gradually with magnitude for large magnitudes. At large distances, the ground motions are typically larger on soil sites than on rock sites, reflecting the effect of amplification due to impedance contrast. However, at close distances where ground motion levels are high, the non-linear behavior of soils tends to offset the impedance contrast effects, to the extent that high frequency ground motions on rock may exceed those on some soils at very close distances to large earthquakes.

\section{Variability in Ground Motions}

There is a large amount of variability in ground motion characteristics due to effects that are more complex than the simple parameterization described above based on magnitude, distance and site category. New methods for analyzing the origins of this variability have provided important insight into the nature of strong ground motions, and indicate the directions in which further research may be able to reduce the uncertainty in the estimation of ground motions for engineering application. Specifically, the random effects approach (Abrahamson and Youngs, 
1992) has been applied to the strong motion data base to separately quantify two sources of variability: the variability in the average ground motions from one earthquake to the next, and the variability in ground motions from one site to another at the same closest distance from a given earthquake. For earthquakes of a given tectonic category larger than about magnitude 6, the event-to-event variability is found to be insignificant compared with the intra-event variability (Youngs et al., 1995). The overall variability thus decreases significantly for the larger magnitudes. The decrease in the variability of ground motion amplitudes with increasing magnitude can have a significant effect on the estimation of ground motions for engineering analysis and design.

This finding indicates that while the average ground motions from one large earthquake are very similar to those of another, there are conditions that cause the ground motions to vary significantly from one location to another at the same distance from a given event. The factors that cause this variability are related to aspects of the earthquake source process, the propagation of seismic waves from the source region to the site region, and the site response that are not contained in the simple magnitude-distance-site category parameterization of standard attenuation relations. In these simple models, these other sources of variability are treated as randomness, whereas they potentially could be treated as resulting from specific effects which may be predictable. While those predictable effects may have uncertainties of their own, in some cases it should be possible to reduce these uncertainties.

For example, current empirical ground motion models are derived from recordings at many sites that fall within a given site category. For a given site category, these models treat site-to-site variability as random. For a given site, strong motion recordings may exist which describe the site response, or a geotechnical boring could potentially be used to characterize the response of the site. Although the site response would still have some uncertainty in these cases, that uncertainty would be less than the standard error of empirical attenuation relations, which represents large site-to-site variations in site response. In this situation, the variability among different sites in the strong motion data set is irrelevant to (and overestimates) the uncertainty in ground motion at the specific site. This is especially important for ground motions having low annual probabilities of exceedance, for which the variability in ground motion is the principal cause of the increase in calculated ground motion level as the annual probability of occurrence decreases. These large calculated ground motion levels in many cases are a reflection of our ignorance of the actual ground motion conditions that exist at a given site rather than an accurate estimate of the potential for large ground motions at the site.

\section{Enhanced Ground Motion Models}

The simple ground motion models described above have a large degree of uncertainty because other conditions that are known to have an important influence on strong ground motions, such as near-fault rupture directivity effects, crustal waveguide effects, basin response effects, and site effects are not treated as parameters of these simple models. In order to reduce the uncertainty in predicting the ground motions at a given site, we need to augment these ground motion prediction models to include more realistic representations of source, path and site effects.

One approach to accounting for these effects in ground motion models is to include them in empirical models by using a larger number of predictive parameters related to source, path and site conditions. Examples of this approach are the empirical models of hanging wall effects and near-fault rupture directivity effects described further below.

Another approach is to use seismologically-based ground motion models that take account of the specific source, path and site conditions. These methods can be used to augment the recorded data used to generate empirical models, or to generate suites of ground motion estimates that can be used to develop independent ground motion models. Ground motion models based on synthetic seismograms can then be used to complement available empirical models. In some regions, the data base of strong motion recordings is too sparse to allow the development of empirical ground motion models. In this case, ground motion attenuation relations are based primarily on seismological models which are described next. Also, considerable progress has been made in understanding and predicting ground motion variability, especially at periods longer than about 1 second, through the modeling of specific effects such as rupture directivity and basin response. By incorporating these effects into ground motion models, in addition to the standard parameters of magnitude, distance and site category, we will be able to reduce the uncertainty in the ground motion estimates for a specified site.

\section{Numerical Ground Motion Models}

Three alternative procedures for estimating strong ground motion are summarized in Table 1. Empirical ground motion attenuation relations of the kind described above are available for predicting the strong motions from earthquakes in tectonically active regions. However, the data base of strong motion recordings in tectonically stable 
regions is too sparse to permit the development of empirical attenuation relations based purely on recorded data. This necessitates the use of seismologically based methods to generate ground motion attenuation relations. The simplest seismologically based method is the Band-Limited White Noise-Random Vibration Theory method (Boore, 1983), often referred to as the stochastic method. This method models ground motion as a time sequence of band limited white noise. A Fourier spectral model of the ground motion is constructed, starting with a model of the source spectrum and modifying its shape by factors to represent wave propagation effects. Current models based on the stochastic method include Atkinson and Boore (1995; 1997), and Toro et al. (1997). There is currently debate among proponents of the stochastic method as to whether the source spectrum is best represented by a Brune spectrum with a single corner frequency (Frankel et al., 1996), or by a model having two corner frequencies (Atkinson, 1993; Atkinson and Silva, 1997).

The broadband Green's function method is a more rigorous procedure that contains fewer simplifications than the stochastic model. By using scaling relations for earthquake source parameters in conjunction with the elastodynamic representation theorem, ground motion time histories are generated without using a priori assumptions about the shape of the source spectrum. The Green's functions that are used in this procedure can be calculated from known crustal structure models, facilitating the use of the procedure in regions where recorded data are sparse or absent.

The broadband Green's function method (e.g., Somerville et al., 1996) has a rigorous basis in theoretical and computational seismology (Helmberger, 1983). The earthquake source is represented as a shear dislocation on an extended fault plane, whose radiation pattern, and its tendency to become subdued at periods shorter than about 0.5 sec, are accurately represented. The spatial and temporal variation of slip of the fault surface is represented using methods described by Somerville et al. (1999). Wave propagation is represented by Green's functions computed for the seismic velocity structure which contains the fault and the site, or by empirical Green's functions derived from strong motion recordings of small earthquakes. These Green's functions contain both body waves and surface waves. The ground motion time history is calculated in the time domain using the elastodynamic representation theorem. This involves integration over the fault surface of the convolution of the slip time function on the fault with the Green's function for the appropriate depth and distance.

An example of broadband simulation of strong ground motions is shown in Figure 1, which compares the recorded and simulated ground motions at Arleta from the 1994 Northridge earthquake. The broadband nature of the simulation is demonstrated by comparing the recorded and simulated acceleration, velocity and displacement time histories. When compared to observed records of actual earthquakes, such ground motion simulation procedures can reproduce the duration, peak accelerations, and short period (less than $1 \mathrm{sec}$.) response spectral accelerations within a factor of about 1.5 , which is comparable to the uncertainty in empirical ground motion prediction models. For peak velocities and response spectral accelerations at periods longer than $1 \mathrm{sec}$, the error in prediction by these simulation methods may be lower than that of empirical ground motion models, especially if rupture directivity and basin response affect the data and are included in the predictions. This kind of validation against recorded data constitutes an important criterion for the selection of ground motion simulation procedures for use in earthquake engineering.

Through the use of these seismological models of strong ground motion, the number of parameters used in the estimation of strong ground motion has grown beyond the simple set of magnitude, distance and site category. For example, in recent ground motion models, the source and path parameters allow for differences in the ground motions between the hanging wall and foot wall of dipping faults, and for the spatial variations in ground motions around faults due to rupture directivity effects. In place of using simple monotonic decay models for the attenuation of ground motion with distance, more complex models that take account of seismic wave propagation in a layered crust have been developed. In place of simple geological descriptors of site conditions or ranges of seismic velocity, the complexity of the interaction of waves arriving at the site with the strongly heterogeneous conditions that characterize the shallow geology of most sites has been recognized and analyzed.

Seismological methods are being increasingly used to constrain those aspects of ground motion prediction that are poorly constrained by recorded strong motion data. This is especially important in stable continental regions where recorded strong motion data are sparse. Even in the most seismically active regions, there are few strong motion recordings close to the large earthquakes that control the seismic design of most structures. The reliability of empirical ground motion attenuation models can be enhanced by augmenting the strong motion data base with strong ground motion time histories simulated for these conditions. 


\section{ADDITIONAL CONDITIONS THAT INFLUENCE GROUND MOTIONS}

While the average ground motions from one large earthquake are very similar to those of another, there are conditions that cause the ground motions to vary significantly from one location to another at the same distance from a given earthquake, as described in Section 3.2. This is reflected in the damage patterns of earthquakes, which often show much more irregularity than would be predicted from simple empirical models. The factors that cause this variability are related to aspects of the earthquake source process, of the propagation of seismic waves from the source region to the site region, and of the site response that are not contained in the simple magnitude-distance-site category parameterization of standard attenuation relations. In these simple models, these other sources of variability are treated as randomness, whereas they potentially could be treated as resulting from specific effects which may be predictable. While those predictable effects may have uncertainties of their own, in some cases it should be possible to reduce these uncertainties. In this section we describe some of these effects, including the source effects of rupture directivity, the path effect of the crustal waveguide, and the site effect of sedimentary basin response.

\section{Near-fault Ground Motions}

The distribution of ground motion amplitudes in the near-fault region is strongly influenced by the fault geometry. For vertical strike-slip faults, rupture directivity effects cause a strong spatial variation in ground motions for a given closest distance to the fault. For dipping faults, there are two prominent effects: the rupture directivity effect and the hanging wall effect. The hanging wall effect is due mainly to the proximity of much of the fault to hanging wall sites. It is most pronounced for periods shorter than about 1 second, and occurs away from the top edge of the fault on the hanging wall side. The rupture directivity effect is due to rupture propagation and radiation pattern effects. It is most pronounced at periods longer than 1 second, and is concentrated over the top edge of the fault. The relationship between the rupture directivity effect and the hanging wall effect is thus complementary both spatially and in period range, enhancing the degree of spatial variation of strong ground motion around dipping faults. In the following, we describe empirical models that have been developed to represent these spatial variations.

\section{Hanging Wall Effects}

Sites on the hanging wall of a dipping fault have closer proximity to the fault as a whole than do sites at the same closest distance on the foot wall. This causes larger short period ground motions on the hanging wall than on the foot wall at the same closest distance. The hanging wall adds to the style of faulting factor for short period ground motions from reverse and thrust earthquakes, which are typically 1.3 to 1.4 times larger than those from strike-slip earthquakes. The empirical model of hanging wall effects developed by Abrahamson and Somerville (1996) distinguishes the ground motions for sites on the hanging wall from those on the foot wall and off the end of the fault rupture. The effect is greatest (a factor of 1.45) in the closest distance range of 8 to $18 \mathrm{~km}$ in the period range of 0 to 0.6 seconds, and decreases to unity at 5 seconds. This model of hanging wall effects is incorporated into the ground motion model of Abrahamson and Silva (1997).

\section{Near-Fault Rupture Directivity Effects}

The propagation of fault rupture toward a site at a velocity that is almost as large as the shear wave velocity causes most of the seismic energy from the rupture to arrive coherently in a single large long period pulse of motion which occurs at the beginning of the record. This pulse of motion represents the cumulative effect of most of the seismic radiation from the fault. The radiation pattern of the shear dislocation on the fault causes this large pulse of motion to be oriented in the direction perpendicular to the fault, causing the strike-normal peak velocity to be larger than the strike-parallel peak velocity. The enormous destructive potential of near-fault ground motions was manifested in the 1994 Northridge and 1995 Kobe earthquakes. In each of these earthquakes, peak ground velocities as high as $175 \mathrm{~cm} / \mathrm{sec}$ were recorded (Figure 2). The period of the near-fault pulses recorded in both of these earthquakes lie in the range of 1 to 2 seconds, comparable to the natural periods of structures such as bridges and mid-rise buildings, many of which were severely damaged.

Forward rupture directivity effects occur when two conditions are met: the rupture front propagates toward the site, and the direction of slip on the fault is aligned with the site. The conditions for generating forward rupture directivity effects are readily met in strike-slip faulting, where the rupture propagates horizontally along strike either unilaterally or bilaterally, and the fault slip direction is oriented horizontally in the direction along the strike of the fault. However, not all near-fault locations experience forward rupture directivity effects in a given event. Backward directivity effects, which occur when the rupture propagates away from the site, give rise to the opposite effect: long duration motions having low amplitudes at long periods. 
The conditions required for forward directivity are also met in dip slip faulting, including both reverse and normal faults. The alignment of both the rupture direction and the slip direction updip on the fault plane produces rupture directivity effects at sites located around the surface exposure of the fault (or its updip projection if it does not break the surface). Consequently, it is generally the case that all sites located near the surface exposure of a dip-slip-fault experience forward rupture directivity when an earthquake occurs on that fault. Unlike the case for strike-slip faulting, where forward rupture directivity effects are expected to be most concentrated away from the hypocenter, dip slip faulting produces directivity effects on the ground surface that are most concentrated updip from the hypocenter.

The effect of forward rupture directivity on the response spectrum is to increase the level of the response spectrum of the horizontal component normal to the fault strike at periods longer than 0.5 seconds. This causes the peak response spectral acceleration of the strike-normal component to shift to longer periods. Near fault effects cannot be adequately described by uniform scaling of a fixed response spectral shape; the shape of the spectrum becomes richer in long periods as the level of the spectrum increases. Near-fault rupture directivity effects can be significant at periods longer than 1 second and at distances less than about $50 \mathrm{~km}$, with the size of the effect depending on the earthquake magnitude and on the geometry of the site in relation to the fault.

Based on an empirical analysis of near-fault data, Somerville et al. (1997) developed modifications to empirical strong ground motion attenuation relations to account for the effects of rupture directivity on strong motion amplitudes and duration. In the near-fault rupture directivity model, amplitude variations due to rupture directivity depend on two geometrical parameters. First, the smaller the angle between the direction of rupture propagation and the direction of waves travelling from the fault to the site, the larger the amplitude. Second, the larger the fraction of the fault rupture surface that lies between the hypocenter and the site, the larger the amplitude. Attenuation relations modified to include directivity effects can be used directly in probabilistic seismic hazard analysis (PSHA) described below. The parameters that control rupture directivity effects are the location and orientation of the fault rupture plane, and the location of the hypocenter on the rupture plane. In modern PSHA codes, all of these parameters are selected in the process of probabilistically characterizing earthquake occurrences on defined faults.

Although the response spectrum provides the basis for the specification of design ground motions in all current design guidelines and code provisions, there is a growing recognition that the response spectrum is not capable of adequately describing the seismic demands presented by brief, impulsive near-fault ground motions. This indicates the need to use time histories to represent near-fault ground motions. Since the strike of the controlling fault is usually known, the differences between ground motions in the directions normal to and parallel to the fault strike can be readily taken into account.

The design and evaluation of critical structures located near faults often uses time histories containing near-fault pulses whose response spectra are compatible with a design response spectrum. It is important to select time histories that appropriately include forward rupture directivity effects. This is true even if time histories are being matched to a design spectrum, and even if the design spectrum explicitly incorporates near-fault conditions, because the spectral matching process cannot build a forward rupture directivity pulse into a record where none is present to begin with. This indicates the need to identify the directivity conditions that control the design spectrum, and select appropriate time histories, because forward rupture directivity effects are present in some but not all near-fault strong motion recordings. As an alternative to the use of ground motion time histories, it may be possible to use domain parameters of the near-fault pulse, such as the period and amplitude of the directivity pulse, in conjunction with the response spectrum, as parameters for specifying near-fault ground motion characteristics for design (Somerville, 1998). These pulse parameters are controlled by source parameters such as the rise time of slip on the fault.

Many analysis procedures assume that the two horizontal components are uncorrelated, and prescribe interchanging the two horizontal components in structural analyses. This is clearly inappropriate for near-fault ground motions, in which there are systematic differences between the strike-normal and strike-parallel components. Interchanging the components can represent physically unrealizable scenarios given the known orientation of the fault. Although near-fault ground displacements contain permanent displacements due to the static displacement field of the earthquake, traditional analog recording systems do not retain these displacements, and in any case they are removed by highpass filtering in traditional processing methods. However, in some cases the permanent ground displacements may be significant for design, and in these cases it is important to specify the correct orientation of the static and dynamic ground displacements. 


\section{Crustal Waveguide Effects}

At close distances (within about $50 \mathrm{~km}$ ), the largest ground motions are caused by waves that travel upward from the earthquake source to the site. However, as distance from the source increases, the direct wave becomes weaker, and the reflections of downgoing waves from interfaces below the source reach the critical angle and undergo total internal reflection. The strong contrast in elastic moduli at these interfaces, especially the Moho, causes these critical reflections to have large amplitudes. The arrival of these critical reflections, beginning at a distance of about $50 \mathrm{~km}$, causes a reduction in the rate of attenuation of ground motion out to distances of about $100 \mathrm{~km}$ or more (Burger et al., 1987). While the elevated ground motion amplitudes in this distance range are usually not large enough by themselves to cause damage, they may produce damage if combined with the amplifying effects of soft soils. The destructive potential of these effects was dramatically demonstrated in the 1989 Loma Prieta earthquake (Somerville et al., 1994), in which major damage was done to buildings and bridges in the San Francisco Bay area located 80 to $90 \mathrm{~km}$ from the earthquake.

The degree of reduction in the rate of attenuation caused by the crustal waveguide, and the distance range over which it occurs, depend on the depth of the earthquake and the thickness and velocity profile of the crust. Consequently, ground motion attenuation characteristics vary depending on the crustal structure and the depth of the earthquake. This new understanding of ground motion attenuation relations has had a large impact on ground motion attenuation relations, especially in regions such as eastern North America where the main basis for attenuation relations is provided by seismologically based models. Whereas earlier seismological models used simple half-space approximations for the attenuation of ground motion ( $1 / \mathrm{R}$ for body waves at close distances; $1 /(\mathrm{R})^{1 / 2}$ for surface waves at larger distances, where $\mathrm{R}$ is distance), all of the current models now take account of the effect of the crustal waveguide. Some methods do so by using attenuation functions derived from recorded weak motion data (e.g. from regional and national earthquake networks; Atkinson and Boore, 1995; 1997), while others use wave propagation calculations based on the regional crustal structure and the earthquake depth (Somerville et al., 1994).

\section{Effects of Sedimentary Basins on Strong Ground Motions}

Many urban regions are situated on deep sediment-filled basins. A basin consists of alluvial deposits and sedimentary rocks that are geologically younger and have lower seismic wave velocities than the underlying rocks upon which they have been deposited. Basins have thicknesses ranging from a hundred meters to over ten kilometers. Waves that become trapped in deep sedimentary basins can potentially be very damaging.

Conventional criteria for characterizing site response are typically based on the distribution of shear wave velocity with depth in the upper 30 meters as determined from field measurements. The response of this soil layer is usually modeled assuming horizontal layering, following the method illustrated on the left side of Figure 3 . The wave that enters the layer may resonate in the layer but cannot become trapped within the layer.

However, at periods longer than one second, seismic waves have wavelengths that are much longer than 30 meters, and their amplitudes are controlled by geological structure having depths of hundreds or thousands of meters which in many cases, such as in sedimentary basins, is not horizontally layered. If the wave enters a basin through its edge, it can become trapped within the basin if post-critical incidence angles develop. The resulting total internal reflection at the base of the layer is illustrated at the top right of Figure 3. In the lower part of Figure 3, simple calculations of the basin response are compared with those for the simple horizontal layered model. In each case, a plane wave is incident at an inclined angle from below. The left side of the figure shows the amplification due to impedance contrast effects that occurs on a flat soil layer overlying rock (bottom) relative to the rock response (top). A similar amplification effect is shown for the basin case on the right side of the figure. However, in addition to this amplification, the body wave entering the edge of the basin becomes trapped, generating a surface wave that propagates across the basin. Current empirical ground motion attenuation relations do not distinguish between sites located on shallow alluvium and those in deep sedimentary basins, and tend to underestimate the ground motions recorded in basins.

Comparing strong ground motion measurements with the results of computer simulations has substantially increased our understanding of basin effects. For example, Figure 4 shows strong motion velocity time histories of the 1994 Northridge earthquake recorded on a profile of stations that begins in the San Fernando Valley, crosses the Santa Monica mountains and extends into the Los Angeles basin (Graves et al., 1998). The two dashed lines indicate the arrival of shear waves from the two predominant subevents of the earthquake. The time histories recorded on rock sites in the Santa Monica Mountains are brief, and are dominated by the direct waves. In contrast, the time histories recorded in the Los Angeles basin have long durations, and the peak velocities are associated not with the direct waves but from later arriving waves that are known to be waves generated at the northern edge of the 
Los Angeles basin (bottom right of Figure 4). Much of the damage in the Los Angeles basin during the Northridge earthquake, including the collapse of the I10 freeway and damage to numerous large buildings in Santa Monica and West Los Angeles, may be attributable to basin effects.

\section{Basin Edge Effects}

The 1994 Northridge and 1995 Kobe earthquakes have shown that large ground motions may be generated by the geological structure of fault-controlled basin edges. The largest ground motions in the Los Angeles basin during the Northridge earthquake were recorded just south of the Santa Monica fault. In this region, the basin-edge geology is controlled by the active strand of the westward striking Santa Monica fault, shown in map view and cross section in the upper part of Figure 4. Despite having similar surface geology, sites to the north of the fault (that are closest to the earthquake source) show relatively modest amplitudes, whereas more distant sites to the south of the fault exhibit significantly larger amplitudes, with a clear and immediate increase in amplification occurring at the fault scarp. The same pattern is dramatically reflected in the damage distribution indicated by red tagged buildings at the top of Figure 4, which shows a large concentration of damage immediately south of the fault scarp in Santa Monica. The strong correlation of ground motion amplification pattern with the fault location suggests that the underlying basin-edge geology is controlling the ground motion response. This is confirmed in the 2D synthetic seismograms shown in Figure 4. The large amplification results from constructive interference of direct waves with the basin-edge generated surface waves.

The 1995 Kobe earthquake provided further evidence from recorded strong motion data, supported by wave propagation modeling using basin edge structures, that ground motions may be particularly large at the edges of fault-controlled basins. Severe damage to buildings due to the Kobe earthquake was observed in a zone about 30 $\mathrm{km}$ long and $1 \mathrm{~km}$ wide, and offset about $1 \mathrm{~km}$ southeast of the fault on which the earthquake occurred (Figure 5). The near-fault ground motions generated by rupture directivity effects in the Kobe earthquake were further amplified by the basin edge effect. This effect was caused by the constructive interference between direct seismic waves that propagated vertically upward through the basin sediments from below, and seismic waves that diffracted at the basin edge and proceeded laterally into the basin (Kawase, 1996; Pitarka et al., 1998). The basin edge effect caused a concentration of damage in a narrow zone running parallel to the faults through Kobe and adjacent cities (Figure 5). The observed band of damage, represented by the zone of JMA Intensity VII shown in panel (a), is reproduced in the map of simulated peak velocity (panel c), generated using a 3D model of the basin edge (panel b). The strong influence of the basin edge is demonstrated in the lower part of the (panel d), which shows vertically aligned time histories from 2D simulations for the actual basin geometry (left side) and a flat layered model with no basin edge (right side). The basin structure produces a strongly asymmetrical zone of large amplitudes along the edge of the basin.

\section{Focusing Effects}

The damage pattern caused by the Northridge earthquake was characterized by pockets of localized damage such as those in Sherman Oaks that were not clearly correlated with surficial soil conditions (Hartzell et al., 1997). These observations have produced important new insights into the causes of localized zones of damage. During the Northridge earthquake, deeper lying geological structure may have had as much influence on strong motion patterns as the upper 30 meters that are conventionally used to characterize site response. This deeper structure may include sedimentary structures in the upper few kilometers of sedimentary basis, as well as topography on the underlying sediment/basement interface. These structures, in the form of folds and buried basins, focus energy (like a lens) in spatially restricted areas on the surface, in some cases becoming the dominant factor in the modification of local ground motion amplitudes.

\section{SCENARIO EARTHQUAKE GROUND MOTION MAPPING}

In the preceding sections, we have described ground motion effects related to various source, path and site characteristics that can affect the ground motions at a site. The challenge of urban hazard mapping is to predict these effects not just at a single site but over an extended region, and to do so with an acceptable level of reliability. The difficulty of this challenge is manifested in the spatially irregular patterns of damage that are typically observed after major earthquakes.

Historically, ground motion maps of past earthquakes have used intensity as the ground motion parameter, because there have not been enough ground motion recordings to make reliable maps of instrumental ground motion parameters, and ground motion simulation procedures have not been sufficiently developed. However, these 
conditions are now changing. For example, the HAZUS Loss Estimation Methodology developed by FEMA in the United States is based on instrumental ground motion parameters, not intensity. This has required the development of instrumental ground motion maps of past earthquakes for use in calibrating loss estimation methodologies. Ground motion maps of earthquakes such as the 1994 Northridge event (Somerville et al., 1995), used in the calibration of HAZUS, demonstrate that strong motion recording stations in some major urban regions may now be sufficiently dense to provide a first order estimate of the distribution of ground motions. However, they are not dense enough to map local variations in ground motions, or provide direct evidence on the correlation of local damage patterns with spatial variations in ground motion levels. Computational methods for seismic zonation can potentially be used to interpolate the recorded data to give a more detailed map of local variations, provided that the subsurface structure is adequately characterized. These methods will need to be validated by the deployment of very dense strong motion networks in selected urban regions.

The conventional approach to zonation of ground shaking hazards in urban regions is to assume that the geology can be characterized by a horizontally stratified medium, and that only the shallowest few tens of meters influence the ground motion characteristics. Seismic zonation then consists of linking together site-by-site estimates of site response generated using methods such as that shown on the left hand side of Figure 3. However, as demonstrated on the right hand side of Figure 3 and illustrated in Figures 4 and 5, this simple approach may significantly underestimate the amplitudes and durations of strong ground motions, especially at periods of about one second and longer, that can become trapped within sedimentary basins due to critical reflections that are set up at the edges of the basin. These effects are due to the geometry of the interface between the sedimentary materials and the underlying crystalline rocks, and cannot be explained by the shallow soil profile alone. Many elements of the urban infrastructure, such as bridges, multi-story buildings, dams and storage tanks, are susceptible to long-period ground motions which may be influenced by basin effects.

New computational procedures have the potential for greatly enhancing the reliability of seismic zonation of urban regions located in sedimentary basins. It is expected that wave propagation computations using finite difference and other methods will largely supplant the use of simple 1-D models of site response in urban seismic zonation. The rapid increase in the speed and memory of computers, and the development of efficient computational methods for modeling seismic wave propagation in laterally varying geological structure, enable us to model the effects of sedimentary basins on ground motions generated by scenario earthquakes. By using finite difference techniques (Graves, 1996), we are able to compute the complete wave field up to a given frequency threshold throughout an entire urban region. This capability has the potential to greatly enhance the seismic zonation of urban regions located on sedimentary basins. Instead of obtaining ground motion estimates at a set of discrete locations using local flat layered geological models, which may be inaccurate because they do not account for the effects of the basin structure, we are able to calculate the seismic wave field throughout the urban region, with the ground motion characteristics at each location reflecting the effects of the laterally varying geologic structure in its vicinity.

\section{PROBABILISTIC GROUND MOTION HAZARD ANALYSIS}

Given the uncertainty in the timing, location and magnitude of future earthquakes, and the uncertainty in the level of the ground motion that a specified earthquake will generate at a particular site, it is often appropriate to use a probabilistic approach to characterize the ground motion that a given site will experience in the future. The probabilistic approach recognizes that there is a finite chance of exceedance of any hazard level, but recognizes that there must be some balance between costs and risks. The probabilistic approach provides a rational way of establishing an acceptable level of the risk, which ultimately must be made by the society at large, or by the regulator or the owner of the facility.

A probabilistic seismic hazard analysis (PSHA) takes into account the ground motions from the full range of earthquake magnitudes that can occur on each fault or source zone that can affect the site. It is calculated from the rate of occurrence of these earthquakes, their distance from the site, and the attenuation of ground motion between the earthquakes and the site. The PSHA numerically integrates this information using probability theory to produce the annual frequency of exceedance of each different ground motion level for each ground motion parameter of interest. More explicitly, the PSHA incorporates for each fault or source zone the following three factors:

o the mean frequency per year of occurrence of each different magnitude level of earthquakes

o the mean frequency per event of each possible source-to-site distance 
o the mean frequency per event of each different level of ground motion from each possible magnitude-distance pair

The PSHA numerically integrates this information using probability theory to produce the annual frequency of exceedance of each different ground motion level for each ground motion parameter of interest. This relationship between ground motion level and annual frequency of exceedance is called a ground motion hazard curve. Uncertainties in each of the input parameters, including the location, geometry, style of faulting and maximum magnitude of earthquake sources, fault slip rates and earthquake recurrence relationships, and ground motion attenuation relationships, can have a large effect on the results and so need to be reflected in the analysis. This is done through the use of logic trees (Kulkarni et al., 1984), which assign probability values to alternative values of these parameters.

The products of a PSHA are ideally suited for performance based design, because they specify the ground motions that are expected to occur for a range of different annual probabilities (or return periods). Each performance objective is associated with an annual probability of occurrence, with increasingly undesirable performance characteristics caused by increasing levels of strong ground motion having decreasing annual probability of occurrence, as represented by the diagonal lines shown in Figure 6.

The relationship between the ground motion level and its annual probability of occurrence is described by a hazard curve, as shown for Boston in Figure 7. This example is derived from the National Seismic Hazard Maps produced by the U. S. Geological Survey (Frankel et al., 1996), which form the basis for the NEHRP Provisions that are used in building codes in the United States. The horizontal axis of Figure 7 shows the peak acceleration, the vertical axis on the left shows the annual frequency of exceedance of the peak acceleration, and the axis on the right shows its inverse, the corresponding average return period.

The hazard curve in Figure 7 is for peak acceleration (response spectral acceleration at zero period) on soil, but the PSHA can produce analogous hazard curves for response spectral acceleration for a suite of periods. From these hazard curves, a suite of response spectra corresponding to several return periods can be constructed, as shown for Boston at the top of Figure 8, to meet the requirements of performance based design.

For performance based design, the ground motions may need to be specified not only as response spectra but also by suites of strong motion time histories for input into time-domain non-linear analyses of structures. This is because response spectrum analysis, upon which nearly all current structural design is based, uses a linear elastic model and therefore does not address the non-linear response that is the essence of building damage and failure. Time histories whose response spectra are scaled to the target response spectra (derived from the USGS maps) at the top of Figure 8 are shown at the bottom of Figure 8. The match between the target spectra and the spectra of the time histories is shown in the middle of Figure 8.

The probabilistic response spectra (top of Figure 8) represent the aggregated contribution of a range of earthquake magnitudes occurring at various rates on each of several discrete faults or seismic source zones located at various distances from the site, and include the effect of random variability in the ground motions for a given magnitude and distance. However, in order to provide ground motion time histories that represent the response spectrum, we must choose one or more discrete combinations of magnitude, distance and _ to represent the probabilistic ground motion. The parameter - is defined as the number of standard deviations above or below the median ground motion level for that magnitude and distance that is required to match the probabilistic spectrum. The magnitude, distance, and _ values are estimated through deaggregation of the probabilistic seismic hazard (Bazzurro and Cornell, 1999; Chapman, 1995; Cramer and Peterson, 1996; Harmsen et al., 1999; McGuire, 1995).

The deaggregations for 1 second period spectral acceleration for $2 \%$ in 50 years are shown for Boston in the form of magnitude, distance and _ combinations in the top part of Figure 9. The contributions to the ground motions are dominated by small earthquakes at close distances, but also include increasingly large earthquake magnitudes at increasingly large distances from Boston. The bottom part of Figure 9 explicitly locates on a map the combinations of magnitude and distance that contribute to the hazard at a single site, Boston. This kind of map facilitates the selection of a suite of magnitudes and distances that are most representative of the hazard. Examples of scaled time histories and response spectra that were used in Phase 2 of the FEMA/SAC Steel Project (Somerville et al., 1997) to represent two different combinations of magnitude and distance affecting Boston are shown in the middle and lower panels of Figure 8. 


\section{CONCLUSIONS}

Even for sites near the best understood faults, earth scientists are not able to predict where and when the next large earthquake is going to occur. Assuming that a specified earthquake does occur, there is also considerable uncertainty in the level of the ground motion that the earthquake will generate at a particular site. The main focus of this paper is to explore the causes of this uncertainty and seek ways to reduce it. Conventional ground motion models predict ground motion parameters using a simplified model in which the effects of the earthquake source are represented by earthquake magnitude; the effects of wave propagation from the earthquake source to the site region are specified by a distance; and the effects of the site are specified by a site category. These ground motion models have a large degree of uncertainty because other conditions that are known to have an important influence on strong ground motions, such as near-fault rupture directivity effects and the response of sedimentary basins, are not treated as parameters of these simple models. In order to reduce the uncertainty in ground motion prediction at a given site, ground motion models are being augmented to include more realistic representations of source, path and site effects through the use of seismologically based strong motion simulation procedures that have been extensively validated against recorded data.

For some purposes, the strong ground motions expected at a site are represented by those resulting from a single earthquake. However, given the uncertainty in the timing, location and magnitude of future earthquakes, for most engineering purposes it is more meaningful to use a probabilistic approach to characterizing the ground motion that a given site will experience in the future. The probabilistic approach is very compatible with current trends in earthquake engineering and the development of building codes, which have embraced the concept of performance based design. Performance based design requires a more comprehensive representation of ground motions than has conventionally been used. For example, ground motions estimates are needed at multiple annual probability levels, and may need to be specified not only by response spectra but also by suites of strong motion time histories for input into time-domain non-linear analyses of structures.

\section{REFERENCES}

Abrahamson, N.A. and K. Shedlock (1997). Overview, ground motion attenuation relations, Seismological Research Letters 68, 9-23.

Abrahamson, N.A. and W.J. Silva (1997). Empirical response spectral attenuation relations for shallow crustal earthquakes, Seismological Research Letters 68, 94-127.

Abrahamson, N.A. and P.G. Somerville (1996). Effects of the hanging wall and foot wall on ground motions recorded during the Northridge Earthquake, Bull. Seism. Soc. Am., 86, S93-S99.

Abrahamson, N.A. and R.R. Youngs (1992). A stable algorithm for regression analysis using the random effects model. Bull. Seism. Soc. Am. 82, 505-510.

Atkinson, G.M. and W.J. Silva (1997). An empirical study of earthquake source spectra for California earthquakes, Bull. Seism. Soc. Am. 87, 97-113.

Atkinson, G. and D. Boore (1997). Some comparisons between recent ground motion relations, Seism. Res. Lett. 68, 24-40.

Atkinson, G. and D. Boore (1995). New ground motion relations for eastern North America, Bull. Seism. Soc. Am. $85,17-30$.

Atkinson, G. (1993). Source spectra for earthquakes in eastern North America. Bull. Seism. Soc. Am. 83, 17781798.

Bazzuro, P. and A.C. Cornell (1999). Disaggregation of seismic hazard, Bull. Seism. Soc. Am., 9, 501-520.

Boatwright, J. and G. Choy (1992). Acceleration source spectra anticipated for large earthquakes in eastern North America, Bull. Seism. Soc. Am., 82, 660-682

Boore, D.M. (1983). Stochastic simulation of high-frequency ground motions based on seismological models of the radiated spectra. Bull. Seism. Soc. Am. 73, 1865-1894

Burger, R.W., P.G. Somerville, J.S. Barker, R.B. Herrmann, and D.V. Helmberger (1987). The effect of crustal structure on strong ground motion attenuation relations in eastern North America, Bull. Seism. Soc. Am., 77, 420439.

Cornell, C.A. (1968). Engineering seismic risk analysis, Bull. Seism. Soc. Am. 58, 1583-1606.

Chapman, M.C. (1995). A probabilistic approach to ground motion selection for engineering design, Bull. Seism. Soc. Am., 85, 937-942.

Cramer, C.H. and M.D. Peterson (1996). Predominant seismic source distance and magnitude maps for Los Angeles, Orange, and Ventura Counties, California, Bull. Seism. Soc. Am., 86, 1645-1649.

Frankel, A., C. Mueller, T. Barnhard, D. Perkins, E. Leyendecker, N. Dickman, S. Hanson and M. Hopper (1996). National Seismic Hazard Maps, June 1996. U.S. Geological Survey Open File Report 96-532. 
Federal Emergency Management Agency (1997). NEHRP Guidelines for the Seismic Rehabilitation of Buildings, FEMA 273.

Federal Emergency Management Agency (1998). 1997 Recommended Provisions for Seismic Regulations for New Buildings and Other Structures, FEMA 302, 337 pp.

Graves, R. W., A. Pitarka, and P. G. Somerville (1998). Ground motion amplification in the Santa Monica area: effects of shallow basin edge structure, Bull. Seism. Soc. Am., 88, 1224-1242.

Graves, R. W. (1966). Simulating seismic wave propagation in 3D elastic media using staggered-grid finite-differences, Bull. Seism. Soc. Am., 86, 1091-1106.

Gutenberg, B. and C.F. Richter (1964). Seismicity of the Earth and Associated Phenomena, $2^{\text {nd }}$. Ed., Princeton University Press, Princeton, N.J.

Harmsen, S., D. Perkins, and A. Frankel (1999). Deaggregation of probabilistic ground motions in the central and eastern United States. Bull. Seism. Soc. Am., 89, 1-13.

Hartzell, S., E. Cranswick, A. Frankel, D. Carver and M. Meremonte (1997). Variability of Site Response in the Los Angeles Urban Area, Bull. Seism. Soc. Am., 1377-1400.

Helmberger, D.V. (1983). Theory and application of synthetic seismograms, in Earthquakes: Observation, Theory and Interpretation, Proc. Int. Sch. Phys. "Enrico Fermi" Course LXXXV, pp. 174-221, eds. Kanamori, H. and E. Boschi, North-Holland, Amsterdam.

Kawase, H. (1996). The cause of the damage belt in Kobe: "The Basin-Edge Effect," constructive interference of the direct S-wave with the basin-induced diffracted/Rayleigh waves, Seismological Research Letters 67, 25-34.

Kobayashi, S., T. Takahashi, S. Matsuzaki, M. Mori, Y. Fukushima, J. Zhao and P.G. Somerville (2000). A spectral attenuation model for Japan using digital strong motion records of JMA87 type. Proc. $12^{\text {th }}$ World Conf. On Earthquake Engineering, Vol. I, pp. 263-270.

Kulkarni, R.B., K. Sadigh and I.M. Idriss (1979). Probabilistic evaluation of seismic exposure, Proceedings of the Second U.S. National Conference on Earthquake Engineering, Stanford, CA, August 22-24, pp. 90-99.

Kulkarni, R.B., R.R. Youngs, and K.J. Coppersmith (1984). Assessment of confidence intervals for results of seismic hazard analysis, Proc. 8 $^{\text {th }}$ World Conf. On Earthquake Engineering, Vol. I, pp. 263-270.

McGuire, R.K. (1995). Probabilistic seismic hazard analysis and design earthquakes: closing the loop. Bull. Seism. Soc. Am., 86, 1275-1284.

McVerry, G.H., J.X. Zhao, N.A. Abrahamson, P.G. Somerville, and N.F. Smith (1999). Modified response spectrum attenuation models for New Zealand, Institute of Geological and Nuclear Sciences Ltd. Client Report.

Pitarka, A., K. Irikura, T. Iwata and H. Sekiguchi (1998). Three-dimensional simulation of the near-fault ground motion for the 1995 Hyogo-ken Nanbu (Kobe), Japan, earthquake. Bull. Seism. Soc. Am. 88, 428-440.

Schwartz, D.P. and K.J. Coppersmith (1984). Fault behavior and characteristic earthquakes from the Wasatch and San Andreas faults, Journal of Geophysical Research 89, 5681-5698.

Somerville, P.G. (1998). Development of an improved representation of near fault ground motion, Proceedings of the SMIP98 Seminar on Utilization of Strong Ground Motion Data, Oakland, CA., September 15, p. 1-20.

Somerville, P.G., K. Irikura, R. Graves, S. Sawada, D. Wald, N. Abrahamson, Y. Iwasaki, T. Kagawa, N. Smith and A. Kowada (1999). Characterizing earthquake slip models for the prediction of strong ground motion. Seismological Research Letters 70, 59-80.

Somerville, P.G., N.F. Smith, R.W. Graves, and N.A. Abrahamson (1997). Modification of empirical strong ground motion attenuation relations to include the amplitude and duration effects of rupture directivity, Seismological Research Letters 68, 199-222.

Somerville, P., N. Smith, S. Punyamurthula, and J. Sun (1997). Development of ground motion time histories for Phase 2 of the FEMA/SAC Steel Project, Report No. SAC/BD-97-04

Somerville, P., C.K. Saikia, D. Wald, and R. Graves (1996). Implications of the Northridge earthquake for strong ground motions from thrust faults, Bull. Seism. Soc. Am., 86, S115- S125.

Somerville, P.G., R.W. Graves, and C.K. Saikia (1995). Characterization of Ground Motions during the Northridge Earthquake of January 17, 1994. Program to Reduce the Earthquake Hazards of Steel Moment Frame Buildings, SAC Report 95-03.

Somerville, P.G., N.F. Smith, and R.W. Graves (1994). The effect of critical Moho reflections on the attenuation of strong motion from the 1989 Loma Prieta earthquake, in "The Loma Prieta, California, Earthquake of October 17, 1989 - Strong Ground Motion, "U.S. Geological Survey Professional Paper 1551-A, A67-A75.

Structural Engineers' Association of California (1996). Recommended Lateral Force Requirements and Commentary, 1996, Sixth Edition.

Toro, G.R., N.A. Abrahamson, and J.F. Schneider (1997). Modeling of strong ground motions from earthquakes in Central and Eastern North America: best estimates and uncertainties. Seism. Res. Lett. 68, 41-57.

Wald, D.J. and T.H. Heaton (1994). Spatial and temporal distribution of slip of the 1992 Landers, California earthquake, Bull. Seism. Soc. Am., 84, 668-691.

Wells, D.L. and K.J. Coppersmith (1994). Analysis of empirical relationships among magnitude, rupture length, rupture area and surface displacement, Bull. Seism. Soc. Am. 84, 974-1002. 
Ward, S.N. (1994). A multidisciplinary approach to seismic hazard in Southern California, Bull. Seism. Soc. Am. 84, 1293-1309.

Youngs, R.R. and K.J. Coppersmith (1984). Implications of fault slip rates and earthquake recurrence models to probabilistic seismic hazard estimates, Bull. Seism. Soc. Am. 75, 939-964.

Youngs, R.R., N.A. Abrahamson, F.I. Makdisi, and K. Sadigh (1995). Magnitude-dependent variance of peak ground acceleration, Bull. Seism. Soc. Am. 85, 1,161-1,176. 